\title{
Design of Technology-Enhanced Learning
}

Integrating Research and Practice 


\section{Design of Technology- Enhanced Learning}

Integrating Research and Practice

\section{By}

Matt Bower

Department of Educational Studies, Macquarie University, Sydney, Australia

\section{emerald PUBLISHING}

United Kingdom - North America - Japan - India - Malaysia - China 
Emerald Publishing Limited

Howard House, Wagon Lane, Bingley BD16 1WA, UK

First edition 2017

Copyright (C) 2017 Emerald Publishing Limited

Reprints and permissions service

Contact: permissions@emeraldinsight.com

No part of this book may be reproduced, stored in a retrieval system, transmitted in any form or by any means electronic, mechanical, photocopying, recording or otherwise without either the prior written permission of the publisher or a licence permitting restricted copying issued in the UK by The Copyright Licensing Agency and in the USA by The Copyright Clearance Center. Any opinions expressed in the chapters are those of the authors. Whilst Emerald makes every effort to ensure the quality and accuracy of its content, Emerald makes no representation implied or otherwise, as to the chapters' suitability and application and disclaims any warranties, express or implied, to their use.

\section{British Library Cataloguing in Publication Data}

A catalogue record for this book is available from the British Library

ISBN: 978-1-78714-183-4 (Print)

ISBN: 978-1-78714-182-7 (Online)

ISBN: 978-1-78714-911-3 (Epub)

ISOQAR certified

Management System,

awarded to Emerald

for adherence to

Environmental

standard

ISOQAR ISO 14001:2004. 
To my wife, who cared not one iota about what I was writing, but generously and kindly made it possible for me to write it.

To my boys, Dan and Zac, who are the apple of my eye.

To educators and researchers everywhere who put their heart into what they do. 


\section{Preface}

Technology is changing everything in our world, including education. People have the ability to access information

1 and communicate anytime and almost anyplace through a range of increasingly powerful and easy to use apps. In education, technology enables students and teachers to rapidly collect data, represent knowledge, share perspectives, digitally construct, and collaborate from almost any location. However, too often the use of technology for learning is presented as a panacea that will solve all educational ills. The reality is that simply using contemporary technologies in education does not guarantee a successful lesson, and in fact, using technology poorly can render a learning experience confusing and meaningless.

As technologies change, it is crucial that educators (school teachers, academics, pre-service teachers, and educational designers) respond in a principled fashion based upon a deep understanding of pedagogical issues, rather than haphazardly based on intuitive or superficial reasoning. Maintaining a focus on pedagogical issues means that educators can avoid being distracted by the novelty of new technologies and concentrate upon how each technology is influencing interaction and learning. Accordingly, in order to develop an accurate and confident command of technology-enhanced learning issues, educators need to understand the research of the field. Similarly, if learning technology researchers want to have far-reaching positive impact, their work needs to penetrate beyond the surface technological features through the underlying learning and teaching issues at stake. Understanding the key issues and research across technologies enables researchers to accurately position their work and demonstrate how it is making a contribution to the field overall.

As a teacher educator and educational researcher specializing in the technology area, I frequently lamented that the technologyenhanced learning literature was disorganized and disparate for educators who wanted to utilize it. This was a problem because most educators simply do not have time to find and distil 
learning technology research relating to their area of focus. Why wasn't there a single resource that synthesized the key learning technology literature in a way that educators could immediately apply? At the same time, educational technology researchers are incredibly time-poor, and while they have immense expertise in their specific sub-areas, the breadth of the technology-enhanced learning literature means that it can be difficult to acquire an accurate sense of the empirical research as a whole. This is particularly true when it comes to understanding research relationships between different technological platforms from an educational design and practice perspective.

This book directly responds to these maladies by drawing technology-enhanced learning research and practice closer together. It does this by synthesizing the general and empirical learning technology literature to clearly identify the key educational potentials, issues, and design considerations relating to technology-enhanced learning. By examining this synthesis of research findings, educators can immediately adopt an evidencebased approach in their designs, and researchers can instantly position their work within the broad context of technologyenhanced learning field.

\section{ABOUT THIS BOOK}

This book has been designed to enable readers to construct an integrated understanding of the key issues surrounding technologyenhanced learning design. Chapter 1 considers the broader context of designing for learning using technology, including its key drivers at school and university levels. Without an understanding of the broader context, it is impossible for educators and researchers to reliably situate their work in a way that responds to social needs. An understanding of the broader socio-political context can also provide motivation for the use of technology in learning. However, the importance of adopting a critical approach to the design of technology-enhanced learning is emphasized.

Chapter 2 briefly introduces the Technology Pedagogy And Content Knowledge (TPACK) framework as a tool for structuring educator thinking. Technology, pedagogy, and content are indeed essential aspects of technology-enhanced learning design, and a focusing on these elements has undoubtedly led to the popularity of the TPACK model. However, the chapter also poses critical reflections on the TPACK framework in terms of its ability to support learning design practice. 
In order to establish a solid conceptual foundation for analyzing technology-enhanced learning, Chapters 3-5 provide a general overview of pedagogy, technology, and content, respectively. Educators and researchers need to have an overarching understand how pedagogy operates on different levels, and the different types of pedagogies at each level, if they are to effectively analyze and utilize different types of technology in education (Chapter 3). Similarly, both educators and researchers need to have general frameworks for thinking about technology selection and utilization, which is why the concept of affordances and multimedia learning effects are interrogated in Chapter 4. The content that we teach and assess may be represented and shared in different ways using technology, and these issues are explored in Chapter 5.

Chapter 6 builds on previous chapters to unpack design thinking - what it involves and why it can be hard to learn. Importantly, teaching is positioned as a design science. Design is the nexus of scientific and artistic thinking, whereby novel and intrinsically valuable solutions emerge based on integrative knowledge. Seeing teaching as a design science helps educators and researchers to maintain a focus on understanding the elements that are most important to the design of effective learning tasks and the processes that help educators to optimize their designs. The field of Learning Design is also introduced, including the various ways it can support educators' design work.

Chapters 7-10 provide comprehensive overviews of educational research relating to Web 2.0, social networking, mobile learning and virtual worlds, respectively. These open, freely available, and relatively easy-to-use technologies have been deliberately chosen for analysis because they are contemporary, have been widely used in education, provide considerable design flexibilities, and have an extensive research base relating to their use. They are also quite different, which means they are interesting to compare and contrast from an educational and research perspective. The benefits, constraints, and design findings for each technology are distilled from the literature, and use cases ('vignettes') are also detailed to offer a clear understanding of issues surrounding learning technology utilization. Research relating to higher education and schools has been integrated on the basis that there is valuable knowledge that can be transferred between each area, though examples have been separated according to educational level so that readers can choose to focus on either university or school use cases if they wish. 
It is important to note that the Web 2.0, social networking, mobile learning, and virtual worlds chapters were composed using a systematic methodology. First, search terms appropriate to each technology were used to scour educational research databases so as to source relevant literature. Papers were selected for inclusion based on the extent to which they constituted highquality empirical research relating to the design and utilization of technology for learning purposes. A 'snowballing' approach was used, whereby relevant references from within selected papers were also considered for inclusion in the review. The benefits, issues, and design implications of all selected papers were then distilled and organized into themes for each technology. This systematic approach was adopted for each technology so that educators and researchers could have confidence that the emergent findings encapsulated the key issues surround technologyenhanced learning design.

Conducting a comprehensive and systematic analysis of Web 2.0, social networking, mobile learning, and virtual worlds also served as the basis for abstracting patterns and principles of technology-enhanced learning design in Chapter 11. By comparing and contrasting the benefits, limitations, and design implications of different technologies it is possible to detect patterns that hold across technologies, but also the nuanced differences of the technologies in application. Then in Chapter 12 future directions of the learning technology field are considered, in terms of the impact of technology trends, the critical role of the teacher, and the need for integrating technology-enhanced learning research and practice.

\section{FOR WHOM IS THIS BOOK USEFUL?}

By integrating technology-enhanced learning research and practice, this book is designed to be useful for practicing educators, pre-service teachers, postgraduate education students, and learning technology researchers.

\section{Practicing Educators}

Practicing educators (academics, school teachers, as well as educational designers) are often looking to extend beyond the anecdotal 'folk pedagogy' that pervades some institutions, and to understand how the research evidence can inform the approaches they would like to adopt. They also often want to know the 
technological options available to them, and are looking for great design ideas. This book addresses these needs.

\section{Pre-Service Teachers}

If our teachers of the future are to be of the highest caliber, they need to adopt a scholarly approach to their study and practice. This book very definitely shifts the focus of pre-service teacher education from a 'how-to' operational emphasis on technological skills to a more research-driven approach. As well, instead of referring pre-service teachers to research papers that often contain methodological and theoretical discussions that are not directly relevant, and that provide no explicit connection to one another, this book presents an integrated narrative that is immediately applicable to teachers in training.

\section{Postgraduate Education and Higher Degree Research Students}

Students completing postgraduate studies and higher degree research in education often desire a concentrated overview of the literature relating to technology-enhanced learning design, which explains how principles from general educational theory have been applied within the learning technology field, and also the empirical findings as they relate to the use of different technological environments. This book satisfies these requirements for them.

\section{Learning Technology Researchers}

Learning technology researchers often want to quickly identify the benefits, issues, and design findings that relate to a particular technology or technologies, and this book provides them with an immediate reference. For instance, a researcher interested in motivation or community building or digital skills or peer feedback can quickly identify the key effects for Web 2.0, social networking, mobile learning, and virtual worlds, with links back to the underlying literature. Systematically abstracting themes across technologies in this book also constitutes new knowledge for the technology-enhanced learning field, enabling researchers to acquire a more accurate sense of the literature and better situate their work. The range of practice considerations outlined in the book may also assist researchers to better respond to the real issues confronting educators and hence optimize the impact of their technology-enhanced learning research. 


\section{FORWARD REMARKS}

There is often a lamentable divide between academic research and coal-face teacher practice, as though either research alone or field-based expertise hold the crucible of pedagogical wisdom when it comes to educational technology utilization. The approach adopted by this book is that research and practice are mutually informing, inextricably valuable to each other, and need to be synergistically applied in order to achieve the best educational results. In order for the technology-enhanced learning field to make greatest progress researchers and practitioners need to be working more closely together, and indeed position themselves as both educators and researchers.

We are in an exciting time in history, challenged by both increasingly rapid changes in technology and mounting pressure to prepare students for an unknown future. By offering an evidence-based and integrated portrayal of how technologies affect learning, this book is designed to provide a common foundation for educators and researchers to confidentially respond to contemporary technological and pedagogical challenges together. I hope you enjoy the book and find it useful, and I welcome your comments and feedback. 


\section{Acknowledgments}

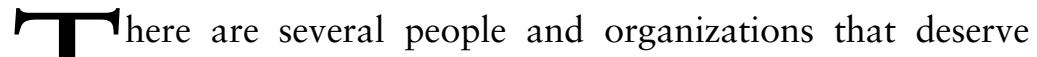
thanks for their help in making this book a reality.

Extensive thanks goes to Professor John Hedberg for his wise feedback on drafts of this book and his kind-hearted mentorship over many years. Dr Michael Stevenson also deserves immense thanks for his detailed and insightful advice on the manuscript - it is a privilege to work with such a talented educator and rising-star researcher. Thank you also to Karen Woo, who generously provided ideas and suggestions on early versions of this book.

Throughout my career, there have been several eminent learning technology experts who have serendipitously conspired to support me, without thought for personal recompense. These include, but are not limited to, Professor Diana Laurillard, Professor Peter Goodyear, Emeritus Professor Tom Reeves, Professor Peter Albion, Professor Barney Dalgarno, Professor Gregor Kennedy, Professor Lori Lockyer, Professor James Dalziel, and of course, Professor John Hedberg. Enormous thanks to each of you for your generous guidance over the years, and more broadly for the positive contribution that you have made to the field of technology-enhanced learning.

Thanks also to Macquarie University for kindly providing me with a six-month sabbatical to write this book. And finally, thank you to the team at Emerald Publishing, who have the open-mindedness to support the books that academics want to write, and the experience to bring them to fruition. 


\section{Foreword}

T $\mathrm{n}$ this book, Matt has successfully coalesce the processes, design ideas, and recent research into a coherent framework that can provide guidance to teachers and academics who seek to maximize the impact of the wonderful technologies and tools we have in modern education. Matt explores the influencing theories and links their contributions to a range of research topics. He seeks not to fall into formulaic approaches or algorithms of the earlier learning sciences, but rather to clearly explore the nuances of design options. When exploring the range of technologies that can be interwoven in modern learning design, he investigates recent technologies that have had successful research studies around them to ensure that the discussion is well argued with evidence and exemplars of effective practice.

The discussion is carefully situated in contexts that employ interesting mixes of technology, pedagogy, and well-chosen theoretical ideas. The discussion links new ideas that underpin recent clever innovative exemplars. Great learning designers will use the ideas in this book to generate learning activities that are innovative and award winning. Activities that effectively employ the attributes of technologies, links to theories of their best design and how they support learning in different curriculum contexts.

John G Hedberg

Sydney, 2017 